Article

\title{
Study on Fabrication of ZnO Waveguide Layer for Love Wave Humidity Sensor Based on Magnetron Sputtering
}

\author{
Changbao Wen *, Taotao Niu, Yue Ma, Nan Gao and Feng Ru \\ Institute of Micro-Nanoelectronics, School of Electronics and Control Engineering, Chang'an University, \\ Xi'an 710064, China; 2016132055@chd.edu.cn (T.N.); 2017232040@chd.edu.cn (Y.M.); \\ 2017232036@chd.edu.cn (N.G.); fengru@chd.edu.cn (F.R.) \\ * Correspondence: estlab@chd.edu.cn; Tel.: +86-159-0296-2067
}

Received: 27 July 2018; Accepted: 8 October 2018; Published: 10 October 2018

\begin{abstract}
The $\mathrm{ZnO}$ waveguide layer for the Love wave humidity sensor was fabricated by radio frequency (RF) magnetron sputtering technique using $\mathrm{ZnO}$ as the target material. To investigate the effect of $\mathrm{RF}$ magnetron sputtering temperature on the $\mathrm{ZnO}$ waveguide layer and Love wave device, a series of Love wave devices with $\mathrm{ZnO}$ waveguide layer were fabricated at different sputtering temperatures. The crystal orientation and microstructure of $\mathrm{ZnO}$ waveguide was characterized and analyzed, and the response characteristics of the Love wave device were analyzed by network analyzer. Furthermore, a humidity measurement system is designed, and the performance of the Love wave humidity sensor was measured and analyzed. The research results illustrate that the performance of the $\mathrm{ZnO}$ waveguide layer is improved when the sputtering temperature changes from $25{ }^{\circ} \mathrm{C}$ to $150{ }^{\circ} \mathrm{C}$. However, when the sputtering temperature increases from $150{ }^{\circ} \mathrm{C}$ to $200^{\circ} \mathrm{C}$, the performance of the $\mathrm{ZnO}$ waveguide layer is degraded. Compared with the other sputtering temperatures, the $\mathrm{ZnO}$ waveguide layer fabricated at $150{ }^{\circ} \mathrm{C}$ has the best c-axis orientation and the largest average grain size $(53.36 \mathrm{~nm})$. The Love wave device has the lowest insertion loss at $150^{\circ} \mathrm{C}$. In addition, when the temperature of the measurement chamber is $25^{\circ} \mathrm{C}$ and the relative humidity is in the range of $10 \%$ to $80 \%$, the fabricated Love wave humidity sensor with $\mathrm{ZnO}$ waveguide layer has good reproducibility and long-term stability. Moreover, the Love wave humidity sensor has high sensitivity of $6.43 \mathrm{kHz} / \mathrm{RH}$ and the largest hysteresis error of the sensor is $6 \%$.
\end{abstract}

Keywords: Love wave device; humidity sensor; $\mathrm{ZnO}$ waveguide layer; magnetron sputtering

\section{Introduction}

Love wave, which is one of the shear horizontal waves, can be excited by the inter-digital transducer (IDT) deposited on a semi-infinite piezoelectric substrate and propagates in the waveguide layer [1,2]. In the Love wave device, the direction of the particle vibration of the Love wave is parallel to the surface of the substrate, and the energy is mainly concentrated in the waveguide layer. Because the coupling effect between the substrate surface and the waveguide layer load is very poor [3,4], the Love wave device can not only be used as a gas material sensor, but also can measure the humidity in the presence of liquid or gas-liquid coexistence, which other humidity sensors cannot do [5-7]. In addition, the Love wave humidity sensor has the advantages of fast response and small size. Therefore, it has been widely used in biosensor and analytical chip [8-10].

The Love wave humidity sensor requires that the shear velocities and densities of the waveguide layer materials are smaller than those of the piezoelectric substrate materials, and the waveguide layer materials were required to have good elastic properties and weak acoustic wave absorption 
performance [11-13]. At present, some materials can be used as a waveguide layer of the Love wave device, such as polyimide (PI), poly methyl methacrylate (PMMA), silicon dioxide $\left(\mathrm{SiO}_{2}\right)$ and zinc oxide $(\mathrm{ZnO})$ [14-17]. In these materials, $\mathrm{ZnO}$ is a kind of piezoelectric material with positive temperature coefficient, which can improve the electromechanical coupling performance, the conversion efficiency, and the temperature characteristics of the Love wave humidity sensor. Furthermore, the $\mathrm{ZnO}$ waveguide layer possesses advantages of high surface free energy, the strong adsorption capacity, the good biocompatibility and the good hydrophilic [18]. It can provide a good biological activity surface for biomolecules as a waveguide layer. Therefore, the Love wave device with $\mathrm{ZnO}$ waveguide have been applied to humidity sensors and biosensors [19,20].

The $\mathrm{ZnO}$ waveguide layer can be fabricated by various techniques, such as chemical vapor deposition [21], Sol-Gel process [22], and magnetron sputtering technique [23,24]. Although the chemical vapor deposition and Sol-Gel process have the advantages of the low cost and easy fabrication, the poor quality of film and the poor reproducibility are also presented. Thus, these two methods are not suitable for the fabrication of high quality and the large number of devices. Although the fabrication of $\mathrm{ZnO}$ waveguide layer by magnetron sputtering technique is complicated and expensive, the $\mathrm{ZnO}$ waveguide layer fabricated by this method has the advantages of high quality and good c-axis orientation [25]. Moreover, this method is a planar fabrication technique with low material cost and good adhesion ability of the substrate, so it can satisfy the requirements of large scale and industrial production of devices.

Based on these advantages of $\mathrm{ZnO}$ as the waveguide layer in the Love wave device and the characteristics of $\mathrm{ZnO}$ waveguide layer, a fabricated scheme of $\mathrm{ZnO}$ waveguide layer for the Love wave device based on magnetron sputtering technique is presented. The influence of sputtering temperature on $\mathrm{ZnO}$ waveguide layer and the Love wave device are analyzed by experiments. Furthermore, a humidity measurement system was designed to study some important characteristics of the Love wave device used as humidity sensor.

\section{Schematic Diagram of Love Wave Humidity Sensor}

Figure 1 shows the schematic diagram of the Love wave humidity sensor. Where $S$ is a piezoelectric substrate and $\mathrm{P}$ is a $\mathrm{ZnO}$ waveguide layer. The $\mathrm{IDT}_{\mathrm{i}}$ and $\mathrm{IDT}_{\mathrm{o}}$ are the input and output transducer respectively, which are located on the piezoelectric substrate $\mathrm{S}$ and are covered in the $\mathrm{ZnO}$ waveguide layer P. The $\mu_{s}$ and $\rho_{s}$ are the shear modulus and density of the piezoelectric substrate material, and the $\mu_{p}$ and $\rho_{p}$ are the shear modulus and density of the $\mathrm{ZnO}$ waveguide material. The $h$ is the thickness of the waveguide layer. The $\mathrm{X}, \mathrm{Y}$ and $\mathrm{Z}$ are the three-dimensional coordinate parameters. The MSC is a multistrip coupler which consists of a set of parallel metal strips fabricated on the piezoelectric substrate. In the actual Love wave device, owing to inverse piezoelectric effects of piezoelectric crystals, the IDT $\mathrm{T}_{\mathrm{i}}$ excites not only the Love wave propagating along crystals surface, but also bulk acoustic wave (BAW) that has higher frequency than that of the Love wave signal. The BAW affects the performance of the sensor, such as producing some ripples and spurious components in response curve. According to the Reference [26], the Love wave excited by the $\operatorname{IDT}_{i}$ can be transferred to the lower half of the MSC under certain conditions while does not affect the propagation path of the BAW and output from the top half of the MSC. Therefore, we use MSC to separate the Love wave and BAW into two sound paths, which reduces the parasitic response of BAW and improves the performance of the Love wave device.

When the excitation signal is applied to the input transducer $\mathrm{IDT}_{\mathrm{i}}$, a Love wave propagating in the $\mathrm{ZnO}$ waveguide layer $\mathrm{P}$ along the $\mathrm{X}$-axis is generated by the inverse piezoelectric effect of the piezoelectric substrate $S$. Because the Love wave is a shear horizontal wave, when the semi-infinite substrate occupies the space of $Z<0$ and the waveguide layer occupies the $(0, h)$ area, the change in particle displacement only exists in the area of the $(0, h)$, without any displacement components in the normal direction of the substrate. In this case, the energy loss is low. 


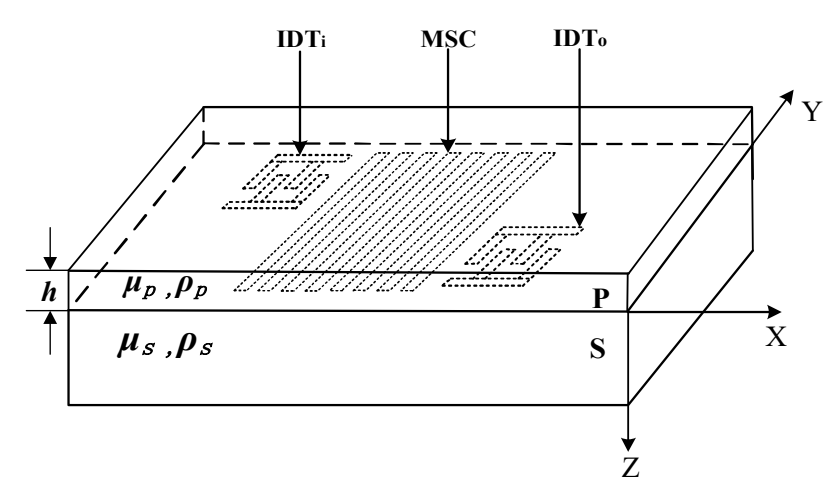

Figure 1. Schematic diagram of the Love wave humidity sensor.

When the Love wave humidity sensor is operating, the propagation velocity of the Love wave is affected by the mass of the material loading on the device, the applied electrical signal, the mechanical properties of the substrate material and the external environment factors. The intrinsic relationship as shown in following equation [27]:

$$
\frac{\Delta v}{v}=\frac{1}{v}\left[\frac{\partial v}{\partial_{\text {mass }}} \Delta_{\text {mass }}+\frac{\partial v}{\partial_{\text {elec }}} \Delta_{\text {elec }}+\frac{\partial v}{\partial_{\text {stru }}} \Delta_{\text {stru }}+\frac{\partial v}{\partial_{\text {env }}} \Delta_{\text {env }}\right]
$$

where $v$ is the propagation velocity of the acoustic wave in the device and $\Delta v$ is the variation of acoustic propagation velocity. $\Delta_{\text {mass }}$ is the mass change of substance loading on the acoustic wave propagation path. $\Delta_{\text {elec }}$ is the variation of electrical signal applied to the device. $\Delta_{\text {stru }}$ is the variation of structural parameters of piezoelectric materials which include resistance and dielectric constants and so on. $\Delta_{e n v}$ is the variation of the environmental parameters of the device. In the Love wave device, the relationship between the acoustic wave propagation velocity and the center frequency of device is given by Equation (2):

$$
\frac{\Delta f}{f_{0}}=\frac{\Delta v}{v}
$$

where $f_{0}$ is the center frequency of device, and $\Delta f$ is the frequency shift of the center frequency.

According to Equations (1) and (2), when the $\mathrm{ZnO}$ waveguide layer in the Love wave humidity sensor has an adsorption effect on the water vapor, the mass and structural parameters of the $\mathrm{ZnO}$ waveguide layer will change due to adsorbing the measured materials. The change will cause the change of acoustic wave propagation velocity in the Love wave device, and further leads to the change of the center frequency of the Love wave device. While the frequency shift is determined by humidity, thus the change in humidity can be measured indirectly by measuring the frequency shift.

\section{Experiments}

\subsection{Fabrication of $\mathrm{ZnO}$ Waveguide Layer}

The most commonly used piezoelectric crystal materials in Love wave devices are quartz, $\mathrm{LiNbO}_{3}$ and $\mathrm{LiTaO}_{3}$. Compared with quartz and $\mathrm{LiTaO}_{3}, \mathrm{LiNbO}_{3}$ has higher piezoelectric coefficient, electromechanical coupling coefficient and lower sound attenuation. Moreover, it is reported that the parasitic level of the Love wave is the lowest when the substrate is $128^{\circ} \mathrm{YX}-\mathrm{LiNbO}_{3}$, so the Love wave device based on $128^{\circ} \mathrm{YX}-\mathrm{LiNbO}_{3}$ has the lower insertion loss and better performance. Therefore, the $128^{\circ} \mathrm{YX}-\mathrm{LiNbO}_{3}$ crystal with $\mathrm{k}^{2}=5.5 \%$ is used as the piezoelectric substrate material of the device.

To suppress the effect of secondary load caused by the electrode quality, the aluminum (Al) with low mass and resistivity is chosen as the IDT electrode material. The Al films were fabricated by direct current sputtering technique and a pair of IDTs was fabricated on the $128^{\circ} \mathrm{YX}-\mathrm{LiNbO}_{3}$ by the ultraviolet (UV) exposure method. The design parameters of the Love device are shown in Table 1. 
The thickness of the $\mathrm{ZnO}$ waveguide layer affects the sensitivity and the insertion loss of the Love wave device $[28,29]$. To obtain higher sensitivity and lower insertion loss, the thickness of the device is designed to be $3 \mu \mathrm{m}$.

The $\mathrm{ZnO}$ waveguide layer was fabricated by the JGP450 magnetron sputtering system. The JGP450 magnetron sputtering system is manufactured by Shenyang scientific instrument Co., Ltd. Chinese Academy of Sciences, and it consists of a sputtering vacuum chamber, magnetron sputtering target, substrate water cooling heating table, working gas path, pumping system, installation machine, vacuum measurement, film thickness monitoring system, and electronic control system. Its limiting vacuum degree is not greater than $6.67 \times 10^{-5} \mathrm{~Pa}$. The target material is the $\mathrm{ZnO}$ with a purity of $99.99 \%$. The sputtering parameters are listed in Table 2.

Table 1. Design parameters of the Love device.

\begin{tabular}{ccc}
\hline & Electrode width $/ \mu \mathrm{m}$ & 4.888 \\
\multirow{2}{*}{ IDTi } & Electrode gap $/ \mu \mathrm{m}$ & 4.888 \\
& Number of electrode pairs & 128 \\
& Maximum acoustic aperture $/ \mathrm{mm}$ & 1.5212 \\
\hline \multirow{3}{*}{ Multistrip coupler (MSC) } & Electrode width $/ \mu \mathrm{m}$ & 7.16 \\
& Electrode gap $/ \mu \mathrm{m}$ & 7.16 \\
& Number of electrode pairs & 103 \\
\hline \multirow{2}{*}{ IDTo } & Electrode width $/ \mu \mathrm{m}$ & 4.888 \\
& Electrode gap $/ \mu \mathrm{m}$ & 4.888 \\
& Number of electrode pairs & 128 \\
& Maximum acoustic aperture $/ \mathrm{mm}$ & 1.5212 \\
\hline
\end{tabular}

Table 2. Sputtering parameters.

\begin{tabular}{cc}
\hline Sputtering Parameter & Value \\
\hline Power & $120 \mathrm{~W}$ \\
Time & $200 \mathrm{~min}$ \\
Pressure & $1.2 \mathrm{~Pa}$ \\
Temperature & $150^{\circ} \mathrm{C}$ \\
\hline
\end{tabular}

The fabrication process of the $\mathrm{ZnO}$ waveguide layer mainly includes four steps. Firstly, place the substrate and target. Secondly, pumping the vacuum of the sputtering chamber to $4.0 \times 10^{-4} \mathrm{~Pa}$ by rough pumping and fine pumping. Thirdly, sputtering of the $\mathrm{ZnO}$ waveguide layer. The sputtering pressure is $1.2 \mathrm{~Pa}$, the sputtering power is $120 \mathrm{~W}$, and the sputtering time is about $200 \mathrm{~min}$. Finally, complete the sputtering of the $\mathrm{ZnO}$ waveguide layer and take out the device. Figure 2 shows the Love wave device with $\mathrm{ZnO}$ waveguide layer fabricated at the sputtering temperature of $150{ }^{\circ} \mathrm{C}$.

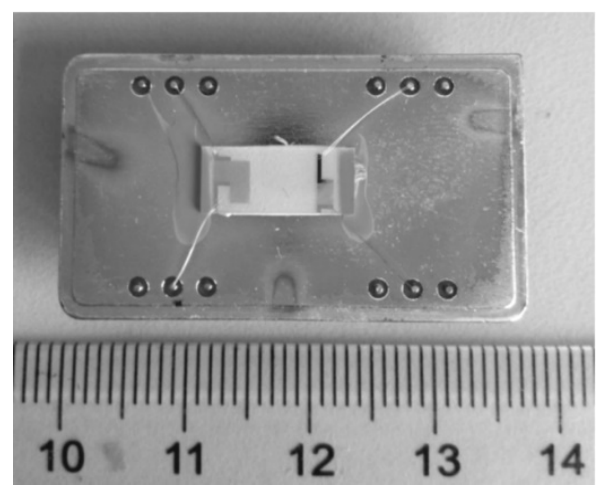

Figure 2. Love wave device with $\mathrm{ZnO}$ waveguide layer fabricated at $150{ }^{\circ} \mathrm{C}$. 
The $\mathrm{ZnO}$ waveguide layer fabricated by magnetron sputtering technique can be regarded as the process of gas atoms or atomic groups from the sputtering target agglomerate into solid on the substrate surface. Whether the growth process of the $\mathrm{ZnO}$ waveguide layer can be sustained or not, the nucleation rate is a key problem.

According to the Boltzmann equation, the nucleation rate of the $\mathrm{ZnO}$ waveguide layer can be written as:

$$
v_{n}=Z n_{1} 2 \pi r \sin \alpha j a_{0} \exp \left[\left(E_{d}-E_{D}-\Delta G\right) / k_{0} T_{s}\right]
$$

where $\mathrm{Z}$ is the Zeldovich correction factor and its value is about $10^{-2} \cdot n_{1}$ is the number of atoms adsorbed by the per unit area and $r$ is the critical nuclear radius. $\alpha$ is the contact angle between the atomic groups and the substrate and $a_{0}$ is the distance between the adsorption sites. $j$ is the intensity of the vaporized gas atoms which incident on the surface of the substrate. $E_{d}, E_{D}$ and $\Delta G$ are the adsorption energy, surface diffusion energy and highest free energy, respectively. $k_{0}$ is the Boltzmann constant and $T_{S}$ is the sputtering temperature.

From Equation (5), in the process of the $\mathrm{ZnO}$ waveguide layer fabricated by magnetron sputtering method, the sputtering temperature has an important effect on the nucleation rate of the $\mathrm{ZnO}$ waveguide layer and it determines the crystal orientation and crystal size of the $\mathrm{ZnO}$ waveguide layer. The nucleation rate will fast if the sputtering temperature too high. In this case, the atoms would not accomplish orderly lattice arrangement, which will affect the crystalline quality of the waveguide layer and the performance of the Love wave device. Therefore, how to control or select an appropriate sputtering temperature is the key to fabricating the high-performance Love wave device.

To research the effect of RF magnetron sputtering temperature on the crystal orientation, microstructure and stress of the $\mathrm{ZnO}$ waveguide and the influence in the performance of the Love wave device. A series of Love wave devices with the $\mathrm{ZnO}$ waveguide layer were fabricated under the sputtering temperatures of $25^{\circ} \mathrm{C}, 50^{\circ} \mathrm{C}, 100^{\circ} \mathrm{C}, 150{ }^{\circ} \mathrm{C}$ and $200^{\circ} \mathrm{C}$, respectively. The others sputtering parameters as shown in Table 2. Then the crystal orientation and microstructure of the $\mathrm{ZnO}$ waveguide layer were analyzed by the $\mathrm{X}$-ray diffraction instrument. The response characteristics of the Love wave device with $\mathrm{ZnO}$ waveguide layer were analyzed by network analyzer.

\subsection{Design of the Humidity Measurement System}

Figure 3 shows the structure diagram of the humidity measurement system. It mainly consists of the closed air chamber, the sensor module, the temperature control module, the humidity control module, the network analyzer, the data processing module, the power module and the display module.

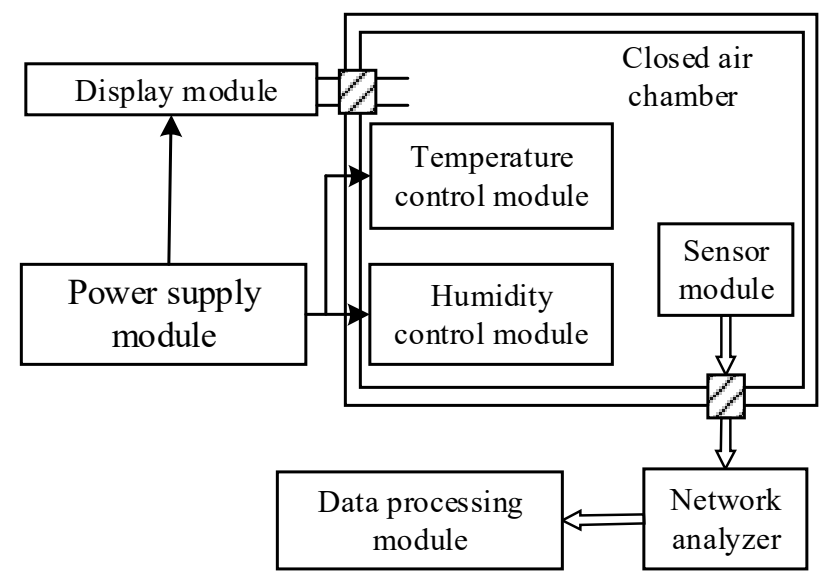

Figure 3. Structure diagram of humidity measurement system. 
As observed from Figure 3, the sensor module, the temperature control module and the humidity control module are in the closed air chamber. The sensor module is a Love wave humidity sensor with the $\mathrm{ZnO}$ waveguide layer fabricated at $150{ }^{\circ} \mathrm{C}$. A 50 -ohm matching is required at both ports of the device for proper connection which has low-reflection loss. The temperature control module is a semiconductor refrigerator and its control circuits. The humidity control module includes a humidification unit and a dehumidifying unit. The other components of the humidity measurement system are located outside the closed air chamber. In these modules, the power module mainly provides power for the display module, the temperature control module and the humidity control module. The display module is composed of the microprocessor and the DHT11 sensor which can measure the temperature and humidity simultaneously. The DHT11 sensor is a digital temperature and humidity sensor, and it is manufactured by waveshare electronics Co., Ltd. Shenzhen, China. When measuring temperature, the resolution is $1{ }^{\circ} \mathrm{C}$, the accuracy is $\pm 2{ }^{\circ} \mathrm{C}$, and the detection range is $0{ }^{\circ} \mathrm{C} \sim 50{ }^{\circ} \mathrm{C}$. When measuring humidity, the resolution is $1 \% \mathrm{RH}$, the accuracy is $\pm 5 \% \mathrm{RH}$, and the detection range is $10 \% \mathrm{RH} \sim 90 \% \mathrm{RH}$. So we can simultaneously measure the temperature and humidity in the closed air chamber by the display module. The spectral characteristics of the sensor were measured by the Agilent E5062A ENA-L RF network analyzer which made in Malaysia and its measurement range is from $300 \mathrm{kHz}$ to $3 \mathrm{GHz}$. The data processing module mainly accomplishes the storage and process of the relevant data. Part of the real measurement system is shown in Figure 4.

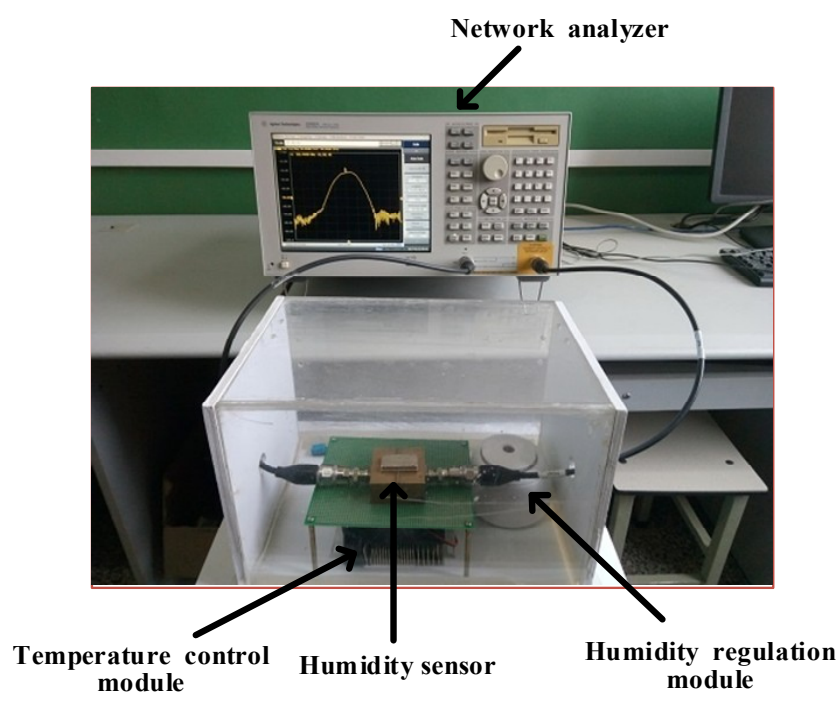

Figure 4. Part of the real measurement system.

\section{Experimental Results and Analysis}

\subsection{Crystal Orientation Analysis of the $\mathrm{ZnO}$ Waveguide Layer}

The c-axis orientation of $\mathrm{ZnO}$ waveguide layer has an important effect in the performance of the Love wave device. The magnetron sputtering technique can be used to fabricate the $\mathrm{ZnO}$ films with good c-axis orientation, high surface evenness and few defects. However, the crystal orientation of the $\mathrm{ZnO}$ waveguide layer would be different because of the different process parameters, such as the sputtering temperature and power. The $\mathrm{X}$-ray diffraction instrument is used to analyze the $\mathrm{ZnO}$ waveguide layers which are fabricated at five different sputtering temperatures. The $\mathrm{X}$-ray diffraction (XRD) spectrum of the $\mathrm{ZnO}$ waveguide layer is shown in Figure 5. 


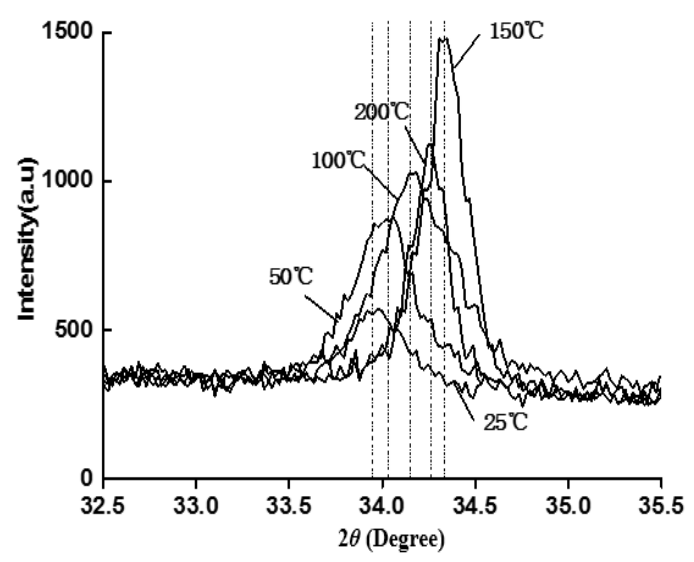

Figure 5. XRD spectra of the $\mathrm{ZnO}$ waveguide layer.

It can be seen from Figure 5 that the $\mathrm{ZnO}$ waveguide layers have the highest diffraction peaks near $34.4^{\circ}$ at the five sputtering temperatures, and the peaks correspond to the non-stress powder (002) plane diffraction peak of $\mathrm{ZnO}$. The results reveal that the $\mathrm{ZnO}$ waveguides growing on the $\mathrm{LiNbO}_{3}$ substrate have (002) preferred orientation at the five sputtering temperatures. That is, the growth of the c-axis is perpendicular to the surface of the substrate.

Furthermore, in the range from $25^{\circ} \mathrm{C}$ to $150{ }^{\circ} \mathrm{C}$, the (002) diffraction angles of the $\mathrm{ZnO}$ waveguide layers gradually approach $34.4^{\circ}$ and the value of the peaks also gradually increase with the temperature rising. When the sputtering temperature goes up to $200{ }^{\circ} \mathrm{C}$, the (002) diffraction angles are deviate from $34.4^{\circ}$ and the peaks value are decreasing. This is because the critical nucleus radius of the film is very small and new nuclei will continue to be produced during the deposition process at a lower sputtering temperature. Moreover, the surface diffusion energy of the atoms or the groups adsorbed on the $\mathrm{LiNbO}_{3}$ is very low, and they cannot migrate to the positions of the lattice where energy are lowest, which leads to the structure of the waveguide layer become loose and emerge some holes of the nanometer scale. This waveguide layer has many disadvantages including many defects, poor c-axis orientation and weak relative intensity of the diffraction peak. These disadvantages eventually lead to the poor acoustic performance. With the increasing of the sputtering temperature, the diffusion of the adsorbed atoms is gradually become the main factor which is affecting the structure and morphology of the films. Atomic diffusion will reduce the number of holes caused by some factors, which will transform the film structure into a good columnar shape and the c-axis becomes better. When the sputtering temperature is too high, the adsorption lifetime of external particles is shortening, and the decomposition rate is increasing, which leads to the reduce of the crystal quality and the c-axis orientation, and eventually the relative intensity of the diffraction peaks become weaker.

\subsection{Microstructure Analysis of the $\mathrm{ZnO}$ Waveguide Layer}

From the theory of nucleation thermodynamics under the condition of non-spontaneous nucleation, the grain size is closely related to the sputtering temperature. To quantitatively analyze the crystallinity of the waveguide layer, the grain size $D$ is estimated based on the Scherrer equation [30]. That is:

$$
D=\frac{K \lambda}{\eta \cos \theta}
$$

where $K=0.94$ is the Scherrer constant and $\lambda=0.1540598 \mathrm{~nm}$ is the wavelength of $X$-ray. $\theta$ is the diffraction angle and $\eta$ is the full-width at half maximum of the diffraction peak. According to the full-width at half maximum of the diffraction peaks in the XRD spectra, the relationship between the different sputtering temperatures and the grain size can be calculated. The results are shown in Table 3. The sputtering time of the five experiments in Table 3 is $400 \mathrm{~min}$. In the process of calculating grain 
size, because the broadening caused by the lattice distortion and instruments cannot be separated effectively, the calculated grain size may be smaller than the real size.

Table 3. Microstructure parameters of the $\mathrm{ZnO}$ waveguide layers at the different sputtering temperatures.

\begin{tabular}{ccc}
\hline $\boldsymbol{T}_{\boldsymbol{s}} /{ }^{\circ} \mathbf{C}$ & $\eta / \mathbf{r a d}$ & $D / \mathbf{n m}$ \\
\hline 25 & 0.00401 & 37.76 \\
50 & 0.00370 & 40.93 \\
100 & 0.00334 & 45.35 \\
150 & 0.00284 & 53.36 \\
200 & 0.00313 & 48.41 \\
\hline
\end{tabular}

As depicted in Table 3, when the sputtering temperature increases from $25^{\circ} \mathrm{C}$ to $150{ }^{\circ} \mathrm{C}$, the grain size also increases and reaches the maximum at $150{ }^{\circ} \mathrm{C}$. If the sputtering temperature continuously increases to $200{ }^{\circ} \mathrm{C}$, the grain size would reduce. In the growth process of the $\mathrm{ZnO}$ waveguide layer, it is difficult to form the crystal with large scale and regular morphology due to the influence of various factors. Thus, the waveguide layer is formed by the gather together of the $\mathrm{ZnO}$ particles. The energy of the internal crystal boundary and the performance of the film depend on the grain size. If the grain size is larger, the crystal boundary will be less, and the defects are fewer. In this case, the film quality is better. The $\mathrm{ZnO}$ waveguide layer is fabricated at $150{ }^{\circ} \mathrm{C}$ has the largest grain size, which indicates that the fabricated $\mathrm{ZnO}$ waveguide layer at $150^{\circ} \mathrm{C}$ has highest crystallinity and best film quality.

During the growth process of the $\mathrm{ZnO}$ waveguide, the stress may change the growth mode of the $\mathrm{ZnO}$, which would affect the surface morphology and c-axis orientation of the $\mathrm{ZnO}$ waveguide layer. The stress would cause the micro-strain, which lead to an increase of the full-width at half maximum. We can assume that the increasing full-width at half maximum is FW(s) caused by micro-strain. To investigate the micro-strain of the $\mathrm{ZnO}$ waveguide layer fabricated at the different sputtering temperatures, the micro-strain curves at each sputtering temperature were analyzed. The result is shown in Figure 6.

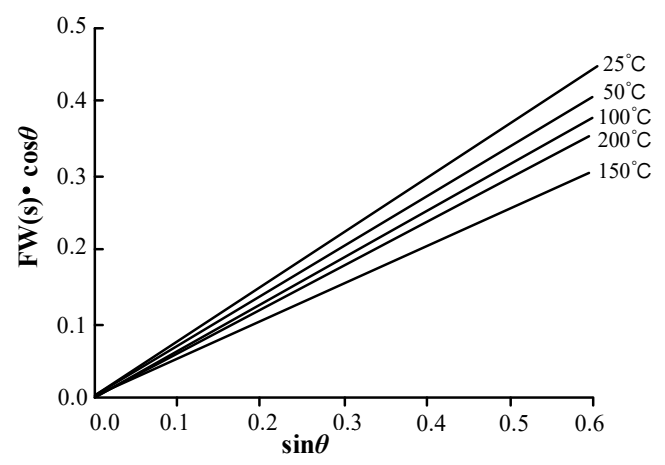

Figure 6. Microscopic strain graphic of the $\mathrm{ZnO}$ waveguide layer.

As can be seen from Figure 6, although the five curves all pass through the origin, the slopes are different because the microscopic strain is different. At a lower sputtering temperature, the c-axis orientation of grains is not completely parallel caused by many holes in the $\mathrm{ZnO}$ waveguide layer. The growth of the columnar crystal is not strictly perpendicular to the substrate and the grains are squeezing with each other, which leads to the increase of the micro-strain. With the sputtering temperature increasing, the c-axis orientation of grains becomes better. Meanwhile, the stress along the c-axis direction and the micros-strain would reduce. These results show that the internal defects in the films are greatly reducing. The reason is that the adsorbent atoms have high diffusion energy and the atoms can diffuse a sufficient distance at a high temperature, thus the atoms can diffuse to the favorable lattice positions eventually. 
Furthermore, the bulk diffusion also exists in the crystal and the waveguide layer would generate the process of recrystallization, which would reduce the density of the defects and improve the c-axis preferred orientation. When the sputtering temperature at $200^{\circ} \mathrm{C}$, the probability of atomic desorption is very high because the adsorption life of the external particles is short. The result leads to part of the waveguide layer surface being rich zinc and a large number of oxygen vacancies existing in the waveguide layer. Finally, the internal defects of the waveguide layer would increase, and the c-axis orientation become poor, while the stress would also increase accordingly. The defects are fewest and internal stress is smallest of the $\mathrm{ZnO}$ waveguide layer fabricated at $150{ }^{\circ} \mathrm{C}$ confirmed by the slope of the line at $150{ }^{\circ} \mathrm{C}$ is smaller than that of the other lines. Therefore, the film quality is better relatively.

\subsection{The Response Characteristics of the Love Wave Device}

The response characteristics of the Love wave device with $\mathrm{ZnO}$ waveguide layer fabricated at different sputtering temperatures are measured by network analyzer. The result is shown in Figure 7. The horizontal and longitudinal axes in Figure 7 are the frequency and insertion loss of the Love wave device, respectively.

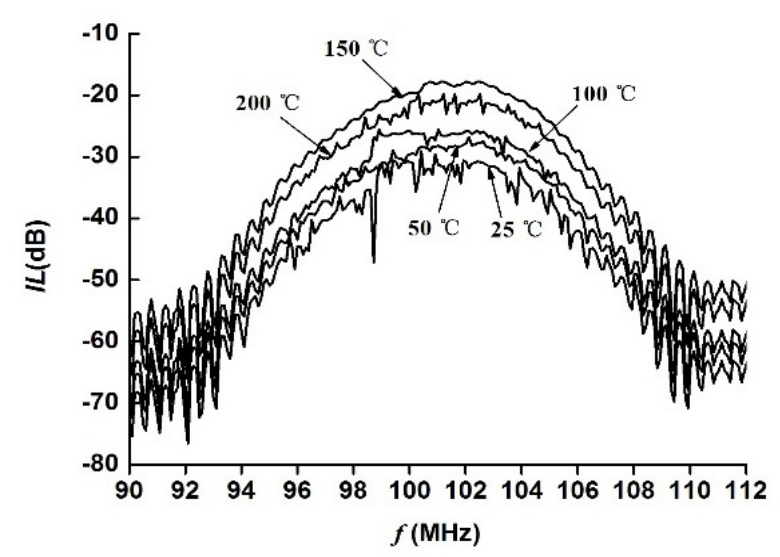

Figure 7. Response characteristics of the Love wave device.

The Figure 7 reveals that the Love wave device fabricated at a lower sputtering temperature has a large fluctuation near the center frequency. With the sputtering temperature increasing, the fluctuation in the band is decreasing but it again increases at $200^{\circ} \mathrm{C}$. Thus, the Love device fabricated at $150{ }^{\circ} \mathrm{C}$ has a better ripple suppression effect in the band.

The insertion loss of the Love wave device is one of the indexes that reflect the performance of the device. Figure 8 shows the effect of the sputtering temperature on the insertion loss.

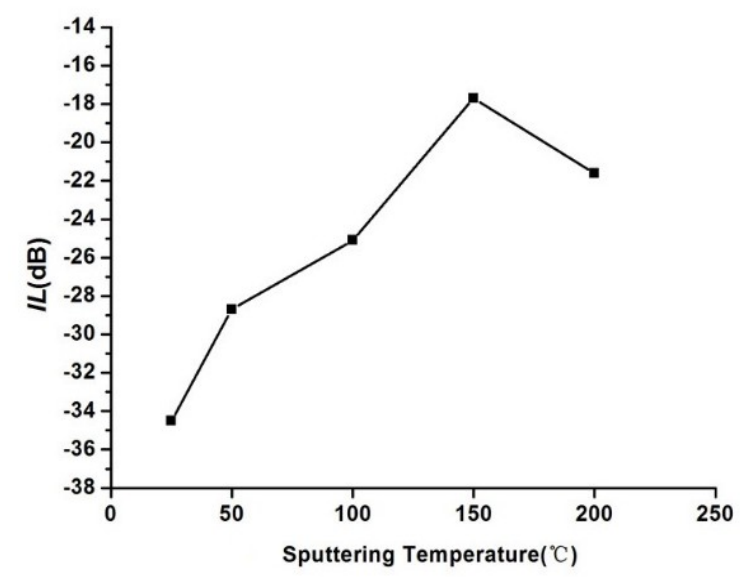

Figure 8. Relationship between the sputtering temperature and the insertion loss. 
It can be seen from Figure 8 that the Love wave device has the lowest insertion loss of $-17.7 \mathrm{~dB}$ at $150{ }^{\circ} \mathrm{C}$, and the insertion loss of the devices is less than $-20 \mathrm{~dB}$ at the other sputtering temperatures. The results caused by the absorption effect of the $\mathrm{ZnO}$ waveguide layer material to the acoustic wave is enhancing. According to the analysis of the $\mathrm{ZnO}$ waveguide layer above, the $\mathrm{ZnO}$ waveguide layer fabricated at $150{ }^{\circ} \mathrm{C}$ has good c-axis preferential orientation, few internal defects and small stress. The delay would exist between the surface and the bottom part of the $\mathrm{ZnO}$ waveguide layer when the acoustic wave propagating, which leads to the strain of the longitudinal direction (thickness direction) in the waveguide layer. If the $\mathrm{ZnO}$ waveguide itself has a relatively high strain, the insertion loss of the device would increase. Therefore, the device has the lowest insertion loss at the sputtering temperature is $150^{\circ} \mathrm{C}$.

\subsection{Characteristic Analysis of the Humidity Sensor}

The center frequency of the Love wave humidity sensor is $102.561 \mathrm{MHz}$ under the normal temperature and humidity. After adjusting the humidity of the closed air chamber to a relative value, the difference between the center frequency of the sensor under this humidity and that under the normal temperature and humidity is regarded as the output signal of the sensor.

The specific measurement process of humidity as follows.

(1) The semiconductor temperature regulator is started to control the temperature of the air chamber at $25{ }^{\circ} \mathrm{C}$, and the temperature of the closed air chamber should be kept at $25{ }^{\circ} \mathrm{C}$ throughout the experiment.

(2) The relative humidity of the closed air chamber is reduced to $10 \%$ by the silica gel desiccant and then keeps for $300 \mathrm{~s}$. The system completes the measurement of the relative humidity when the output signal of the system reaches a stable value.

(3) Each relative humidity was measured by the same method.

Repeatability is an important characteristic of the sensor. To study the repeatability of the Love wave humidity sensor with the $\mathrm{ZnO}$ waveguide layer, the relative humidity of $60 \%$ was measured three times by the Love wave humidity sensor. The test result is shown in Figure 9. In Figure 9, the positive frequency shift represents the increase of the center frequency, and the negative frequency shift represents the decrease of the center frequency. Since the frequency shift is defined as the difference between the center frequency of the sensor under a certain humidity and the center frequency under normal humidity at same temperature. The decrease of the center frequency is due to the humidity in the closed air chamber is lower than normal humidity and the influence of humidity on the $\mathrm{ZnO}$ waveguide layer is weakened. On the contrary, when the humidity is higher than the normal humidity, the central frequency of the device will increase.

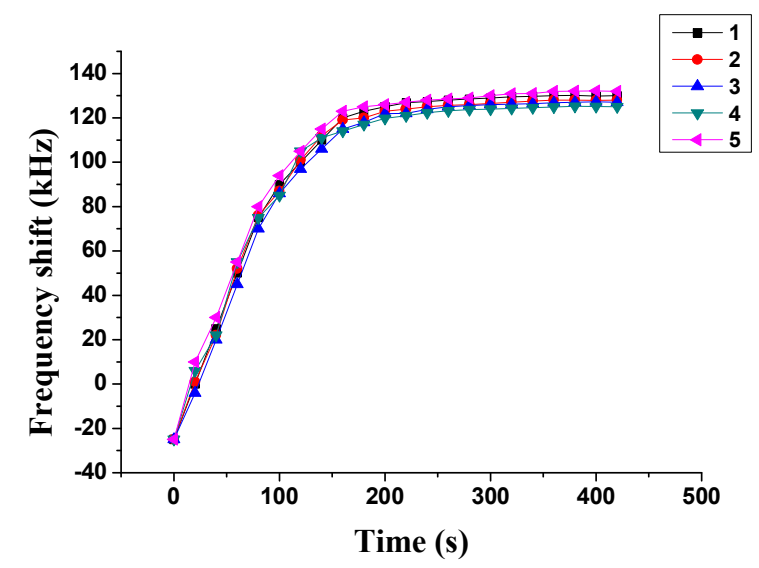

Figure 9. Repeatability of the Love wave humidity sensor at $60 \%$ RH. 
From Figure 9, it can be concluded that the frequency shift of the sensor is changing as the time pass. The trends of the five curves show that the response of the sensor to relative humidity is slowly changing. With the time increasing, the frequency shift of the sensor is increase gradually. Then it tends to be steady at $200 \mathrm{~s}$ and reaches a steady value at $300 \mathrm{~s}$. According to the experimental results, the trends of the three curves are same basically, especially when the time is $0-90 \mathrm{~s}$ and 180-420 s. The results illustrate that the sensor with $\mathrm{ZnO}$ waveguide layer has a good repeatability. If the fabrication process of the $\mathrm{ZnO}$ waveguide layer is improved under the same film thickness, the repeatability of the sensor can be further improved.

To study the relationship between the relative humidity and the frequency shift of the sensor, the humidity of the closed air chamber is increased from $10 \%$ to $80 \%$ stepped with the relative humidity interval of $5 \%$. The frequency shift of the sensor is measured five times at each relative humidity, and then the average value is considered to be the frequency shift at that humidity. The steady value of the system output is recorded and saved at each relative humidity. The result is shown in Figure 10.

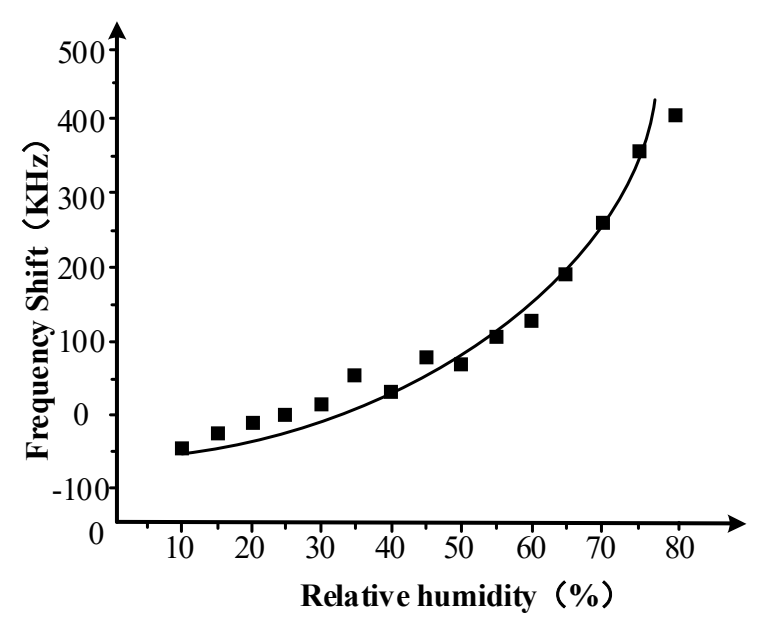

Figure 10. Frequency shift of the sensor change with the relative humidity.

The result of Figure 10 shows that the frequency of the sensor has a one-to-one relationship with the relative humidity of the measuring chamber. In general, the frequency shift of the Love wave humidity sensor is increasing with the relative humidity increasing. The frequency shift is small and has a linear relationship nearly with the relative humidity when the relative humidity is less than $30 \%$. The change in the frequency shift becomes quickly when the relative humidity increases from $40 \%$ to $60 \%$. After the relative humidity goes over $60 \%$, the change of the frequency shift becomes increasingly quick, so the slight relative humidity change would lead to very large frequency shift.

The sensitivity of the sensor is about $6.43 \mathrm{kHz} / \mathrm{RH}$ when the relative humidity is in the range of $10 \%$ to $80 \%$. In addition, the frequency resolution of the network analyzer is $1 \mathrm{~Hz}$, so the Love wave humidity sensor can detect a change of $0.00015 \%$ of the relative humidity theoretically. That is, the test limitation of the sensor is $0.00015 \mathrm{RH} / \mathrm{Hz}$. Therefore, the sensor has high sensitivity and good application prospect.

The moisture absorption and desorption of the Love wave humidity sensor need time; thus, the frequency shift of the sensor will be different in the process of the moisture absorption and desorption when the relative humidity is different, and the other conditions are the same. The hysteresis characteristics were measured at $25^{\circ} \mathrm{C}$ and the results are shown in Figure 11. 


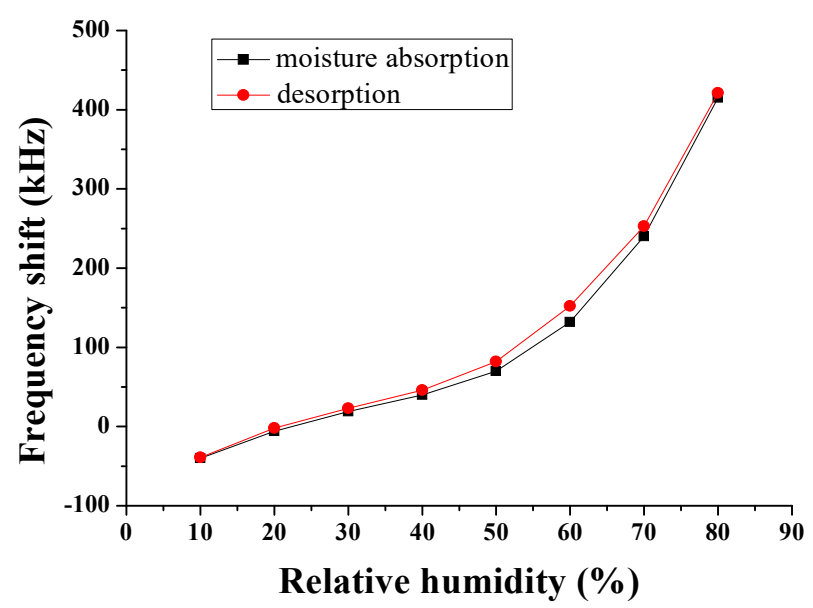

Figure 11. Hysteresis characteristics of the Love wave humidity sensor.

According to Figure 11, the trends of the frequency shift in the process of desorption and moisture absorption is almost the same. The change in the frequency shift is largest and the largest hysteresis error is $6 \% \mathrm{RH}$ when the relative humidity is $60 \%$. The result shows that the hysteresis of the sensor is good.

The humidity response characteristics of the Love wave humidity sensor were measured at $25^{\circ} \mathrm{C}$ and the result is shown in Figure 12. It can be seen from Figure 12 that the frequency shifts of the sensor were $-6 \mathrm{kHz}, 19 \mathrm{kHz}, 40 \mathrm{kHz}, 73 \mathrm{kHz}, 135 \mathrm{kHz}$ and $244 \mathrm{kHz}$ when the relative humidity increased from $10 \%$ to $20 \%, 30 \%, 40 \%, 50 \%, 60 \%$ and $70 \%$, respectively. The $80 \%$ response time is less than 3 min and all the recovery time is less than $30 \mathrm{~s}$, which indicates that the Love wave humidity sensor has good response characteristics.

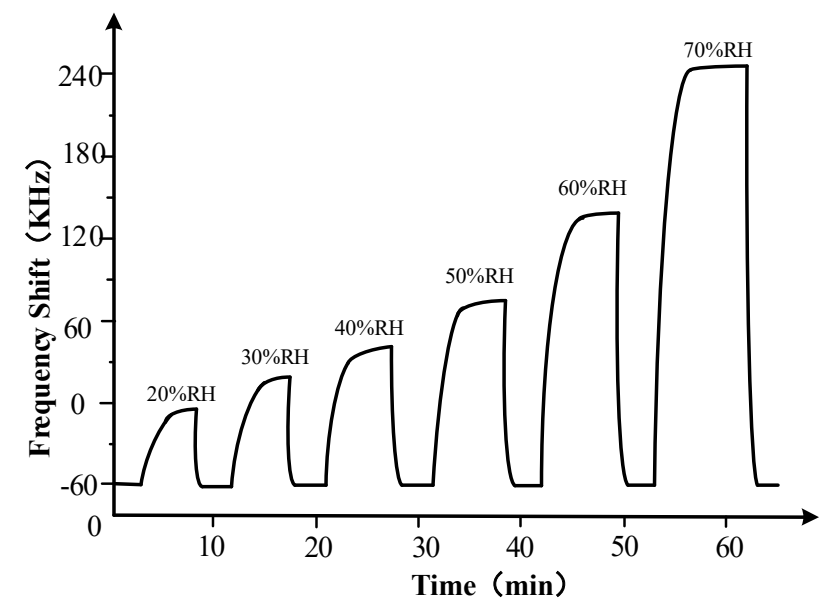

Figure 12. Humidity response characteristics of the Love wave humidity sensor.

To investigate the long-term stability of the Love wave humidity sensor, the sensor was placed in circumstances with relative humidity at $20 \%, 40 \%, 50 \%, 60 \%, 70 \%$ and $80 \%$ for 40 days, respectively. The result is shown in Figure 13. As show in Figure 13, the frequency fluctuation of the sensor is less than $5 \%$ in 40 days under different relative humidity, which indicated that the sensor had good long-term stability. 


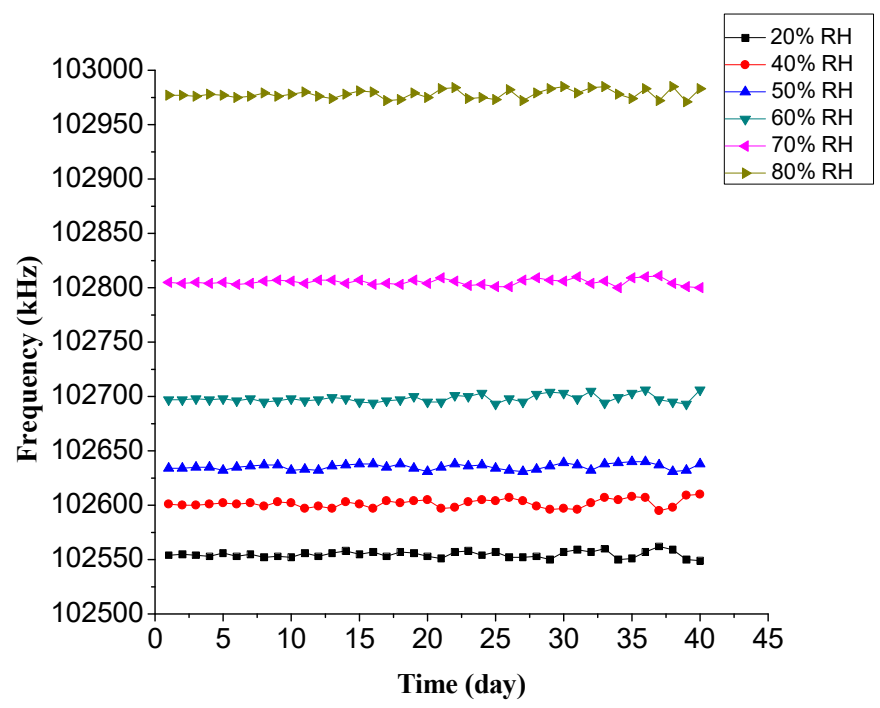

Figure 13. Stability of the Love wave humidity sensor.

\section{Conclusions}

In this paper, a fabrication scheme of the $\mathrm{ZnO}$ waveguide layer in the Love wave device by the magnetron sputtering technique is presented. The influence of the different sputtering temperatures in the performance of $\mathrm{ZnO}$ waveguide layer and the Love wave device is discussed. Then the crystal orientation, grain size and stress of the $\mathrm{ZnO}$ waveguide layer were measured and analyzed. Furthermore, a humidity measurement system is designed and the characteristics of the Love wave device with $\mathrm{ZnO}$ waveguide layer as humidity sensor are analyzed. The results show that the performance of the Love wave device is improved firstly and then is degraded when the sputtering temperature increases from $25^{\circ} \mathrm{C}$ to $200{ }^{\circ} \mathrm{C}$. Meanwhile, the c-axis orientation is highest, and the internal defects are least of the $\mathrm{ZnO}$ waveguide layer fabricated at $150{ }^{\circ} \mathrm{C}$. In addition, the Love wave humidity sensor with $\mathrm{ZnO}$ waveguide layer fabricated at $150{ }^{\circ} \mathrm{C}$ has good reproducibility, fine long-term stability and high sensitivity.

Author Contributions: C.W. conceived and designed the experiments; T.N. and Y.M. performed the experiments; T.N. and N.G. analyzed the data; F.R. contributed materials and analysis tools; and C.W. wrote the paper.

Funding: This research was funded by the National Natural Science Foundation of China (Grant number: 61701044), the Natural Science Basic Research Plan in Shaanxi Province (Grant number: 2018JQ6056 and 2018XNCG-G-01), and the Special Fund for Basic Scientific Research of Central Colleges (Grant number: 300103187051 and 300104283215).

Conflicts of Interest: The authors declare no conflict of interest.

\section{References}

1. Liu, T.W.; Lin, Y.C.; Tsai, Y.C.; Ono, T.; Tanaka, S.; Wu, T. Evidence of a Love wave bandgap in a quartz substrate coated with a phononic thin layer. Appl. Phys. Lett. 2014, 104, 181905. [CrossRef]

2. Li, S.; Wan, Y.; Fan, C.; Su, Y. Theoretical Study of Monolayer and Double-Layer Waveguide Love Wave Sensors for Achieving High Sensitivity. Sensors 2017, 17, 653. [CrossRef] [PubMed]

3. Han, K.; Yuan, Y.J. Mass sensitivity evaluation and device design of a Love wave device for bond rupture biosensors using the finite element method. IEEE Sens. J. 2014, 14, 2601-2608. [CrossRef]

4. Sayago, I.; Matatagui, D.; Fernández, M.J.; Fontecha, J.L.; Jurewicz, I.; Garriga, R.; Muñoz, E. Graphene oxide as sensitive layer in Love-wave surface acoustic wave sensors for the detection of chemical warfare agent simulants. Talanta 2016, 148, 393-400. [CrossRef] [PubMed]

5. Liu, J.S.; Wang, L.J. Dynamics and response of a humidity sensor based on a Love wave device incorporating a polymeric layer. Sens. Actuators B Chem. 2014, 204, 50-56. [CrossRef] 
6. Kovacs, G.; Vellekoop, M.J.; Haueis, R.; Lubking, G.W.; Venema, A. A love wave sensor for (bio)chemical sensing in liquids. Sens. Actuators A Phys. 1994, 43, 38-43. [CrossRef]

7. Dickert, F.L.; Tortschanoffl, M.; Bulst, W.E.; Fischerauer, G. Molecularly Imprinted Sensor Layers for the Detection of Polycyclic Aromatic Hydrocarbons in Water. Anal. Chem. 1999, 71, 4559-4563. [CrossRef]

8. Jakoby, B.; Vellekoop, M.J. Properties of Love waves: applications in sensors. Smart Mater. Struct. 1997, 6, 668-679. [CrossRef]

9. Dejous, C.; Hallil, H.; Raimbault, V.; Lachaud, J.; Plano, B.; Delépée, R.; Favetta, P.; Agrofoglio, L.; Rebière, D. Love Acoustic Wave-Based Devices and Molecularly-Imprinted Polymers as Versatile Sensors for Electronic Nose or Tongue for Cancer Monitoring. Sensors 2016, 16, 915. [CrossRef] [PubMed]

10. Gammoudi, I.; Tarbague, H.; Othmane, A.; Moynet, D.; Rebière, D.; Kalfat, R.; Dejous, C. Love-wave bacteria-based sensor for the detection of heavy metal toxicity in liquid medium. Biosens. Bioelectron. 2010, 26, 1723-1726. [CrossRef] [PubMed]

11. Gammoudi, I.; Blanc, L.; Moroté, F.; Grauby-Heywang, C.; Boissière, C.; Kalfat, R.; Rebière, D.; Cohen-Bouhacina, T.; Dejous, $\mathrm{C}$. High sensitive mesoporous $\mathrm{TiO}_{2}$-Coated Love wave device for heavy metal detection. Biosens. Bioelectron. 2013, 57, 162-179. [CrossRef] [PubMed]

12. Fu, C.; Jung, I.; Yang, S.S.; Lee, K. Towards optimised wireless Love wave biosensor with high sensitivity. Micro Nano Lett. 2012, 7, 1202-1205. [CrossRef]

13. Wang, L.; Liu, J.; He, S. The Development of Love Wave-Based Humidity Sensors Incorporating Multiple Layers. Sensors 2015, 15, 8615-8623. [CrossRef] [PubMed]

14. Turton, A.; Battacharyya, D.; Wood, D. Love-mode surface acoustic wave liquid sensors using a polyimide waveguide layer. In Proceedings of the 2004 IEEE International Frequency Control Symposium and Exposition, Montreal, QC, Canada, 23-27 August 2004; pp. 250-256.

15. Wang, W.; Xie, X.; Chen, G.; Liu, J.L.; He, S.T. Temperature-compensated Love wave based gas sensor on waveguide structure of $\mathrm{SiO}_{2} / 36^{\circ} \mathrm{YX} \mathrm{LiTaO}_{3}$. Smart Mater. Struct. 2015, 24, 065019. [CrossRef]

16. Harding, G.L.; Du, J. Design and properties of quartz-based Love wave acoustic sensors incorporating silicon dioxide and PMMA guiding layers. Smart Mater. Struct. 1997, 6, 716-720. [CrossRef]

17. Trivedi, S.; Nemade, H.B. Simulation of a Love wave device with ZnO nanorods for high mass sensitivity. Ultrasonics 2017, 84, 150-161. [CrossRef] [PubMed]

18. Lan, X.D.; Zhang, S.Y.; Wang, Y.; Li, F.; Shui, X.J. Humidity responses of Love wave sensors based on (1120) $\mathrm{ZnO} / \mathrm{R}$-sapphire bilayer structures. Sens. Actuators A Phys. 2015, 230, 136-141. [CrossRef]

19. Lan, X.D.; Zhang, S.Y.; Fan, L.; Wang, Y. Simulation of SAW Humidity Sensors Based on (1120) $\mathrm{ZnO} / \mathrm{R}-\mathrm{Sapphire}$ Structures. Sensors 2016, 16, 1112. [CrossRef] [PubMed]

20. Zhang, X.; Fang, J.R.; Zou, L.; Zou, Y.C.; Lang, L.; Gao, F.; Hu, N.; Wang, P. A novel sensitive cell-based Love Wave biosensor for marine toxin detection. Biosens. Bioelectron. 2016, 77, 573-579. [CrossRef] [PubMed]

21. Escalante, G.; Juárez, H.; Fernández, P. Characterization and sensing properties of ZnO film prepared by single source chemical vapor deposition. Adv. Powder Technol. 2017, 28, 23-29. [CrossRef]

22. Kamalasanan, M.N.; Chandra, S. Sol-gel synthesis of ZnO thin films. Thin Solid Films. 1996, 288, $112-115$. [CrossRef]

23. Carcia, P.F.; Mclean, R.S.; Reilly, M.H.; Nunes, G.N., Jr. Transparent ZnO thin-film transistor fabricated by $\mathrm{rf}$ magnetron sputtering. Appl. Phys. Lett. 2003, 82, 1117-1119. [CrossRef]

24. Zhu, C.; Li, J.; Yang, Y.; Zhao, X.; Zou, W. Highly moisture and weak-acid resistant Ga-doped ZnO films with titanium dioxide co-doping fabricated by magnetron sputtering. Thin Solid Films 2017, 634, 155-159. [CrossRef]

25. Liu, W.S.; Chen, W.K.; Wu, S.Y.; Hsueh, K.P. Improved crystal quality of transparent conductive Ga-doped $\mathrm{ZnO}$ films by magnesium doping through radio-frequency magnetron sputtering preparation. J. Am. Ceram. Soc. 2014, 97, 473-480. [CrossRef]

26. Marshall, F.G.; Paige, E.G.S. Novel acoustic-surface-wave directional coupler with diverse applications. Electron. Lett. 1971, 7, 460-462. [CrossRef]

27. Hoummady, M.; Campitelli, A.; Wlodarski, W. Acoustic wave sensors: design, sensing mechanisms and applications. Smart Mater. Struct. 1997, 6, 647-657. [CrossRef] 
28. Mchale, G.; Newton, M.I.; Martin, F.; Melzak, K.A.; Gizeli, E. Resonant conditions for Love wave guiding layer thickness. Appl. Phys. Lett. 2001, 79, 3542-3543. [CrossRef]

29. Hu, Y.W.; Shi, J.L.; Jia, H.G.; Wu, Y.H. Love Wave Sensor and the Measurement of Mass Sensitivity. J. Sens. Actuators Chin. 2006, 19, 2126-2129. (In Chinese)

30. Khan, Z.R.; Khan, M.S.; Zulfequar, M.; Khan, M.S. Optical and structural properties of ZnO thin films fabricated by Sol-Gel method. Mater. Sci. Appl. 2011, 2, 340-345. [CrossRef] 